\title{
Development of Schistosoma mansoni worms in mice analyzed by bright field and confocal microscopy
}

\author{
Carla de Lamare Biolchini/ ++ , Renata Heisler Neves*/+++, Maarten Hulstijn, \\ Delir Corrêa Gomes*/+++, José Roberto Machado-Silva/ ${ }^{+} /+++$
}

\begin{abstract}
Laboratório Romero Lascasas Porto, Disciplina de Parasitologia, Departamento de Patologia e Laboratórios, Faculdade de Ciências Médicas, Universidade do Estado do Rio de Janeiro, Rua Prof. Manuel de Abreu 444, $5^{\circ}$ andar, 20550-170

Rio de Janeiro, RJ, Brasil *Laboratório de Helmintos Parasitos de Vertebrados, Departamento de Helmintologia, Instituto Oswaldo Cruz-Fiocruz, Rio de Janeiro, RJ, Brasil
\end{abstract}

The blood flukes of mammals (Digenea: Schistosomatidae) are among trematodes unique whose adult worms have separeted sexes which are dissimilar in appearance. The developmental features, growth and organogenesis of Schistosoma mansoni were studied in Swiss Webster mice by a digital system for image analysis and confocal microscopy. Data so far obtained showed two phases with significative morphological changes at 3-4 weeks postinfection, and a gradual similar development onwards in the reproductive system and tegument. Our male-dependent phase demonstrated that mating occurs before sexual maturing. At week three, the majority of male worms (59\%) had formed the gynaecophoric canal although testicular lobes and tegumental tubercles were absent. By this time, $33 \%$ females had an incipient ovary (without cellular differentiation). At week four, $77.2 \%$ males presented testicular lobes with few germinative cells while $26 \%$ had developing tegumental tubercles. The immature ovary was observed in $69 \%$ females. Suckers followed different pattern of growth between male and females. The size of oral and ventral suckers from six-week-old male worms grew abruptly (3.0 fold) more than that of three-week-old. In female worms, maximum growth was attained at week four, reducing in size thereafter. From sixth week onwards, all specimens showed the fully developed reproductive system. Probably, these features are morphological traits which schistosome has experienced from hermaphrodite to dioecy.

Key words: Digenea - Schistosoma mansoni - development

The Schistosomatidae are unusual trematodes more oftenly dioeceous than hermaphrodite. It is believed that the genus Schistosoma would be evolved from a hermaphroditic trematode of blood system that lived in reptiles of Mesozoic (Basch 1990). Thus, the origin of dioicism would be associated with the origin of endothermy, the development of a more sophisticated immune system in endothermic vertebrates and habitat changes, from arterial to venous blood (Platt \& Brooks 1997). Morphological studies have shown that present-day-females have sacrificed structural elements including locomotory and pharyngeal muscles (Basch 1990). These losses were balanced for a significant dependency on the well-muscled males (Basch 1990) for transportation to the site of egg deposition, feeding (Basch 1990, Ribeiro-Paes \& Rodrigues 1997, Kunz 2001), and possibly haemozoin synthesis (Oliveira et al. 2000). In addition, long-term pairing is wanted for females to maintain their sexual maturity (Basch 1990, Kunz 2001). Several molecular studies have shown that gene expres-

Financial support: Faperj

+Corresponding author: machado@uerj.br

${ }^{++}$Coordination for Higher Level Graduates Improvement (Capes)

${ }^{+++}$Research fellow CNPq

Received 25 May 2006

Accepted 26 June 2006 sion in the vitellaria of females is dependent on signals from the male sexual partner (LoVerde \& Chen 1991, Grevelding et al. 1997) and expression of the gene (p19) depends on pairing with a male (Michel et al. 2003). However, the morphological adaptive significance of these determinants has seldom been demonstrated in rigorous details. This work was performed to shed light on the growth and development of S. mansoni in the final host, discussing these features and which schistosome has experienced from hermaphrodite to dioecy.

\section{MATERIALS AND METHODS}

Parasites and hosts - A Belo Horizonte (Brazil) strain of $S$. mansoni was maintained at the Malacology Department (Instituto Oswaldo Cruz, Rio de Janeiro, Brazil) using Biomphalaria glabrata snails and Swiss Webster Mus musculus as intermediate and definitive hosts, respectively. Laboratory mice from the Animals Breeding Center- Fundação Oswaldo Cruz (Fiocruz, Rio de Janeiro, Brazil) were used. Mice were housed in polypropylene boxes $(40 \times 33 \mathrm{~cm})$ with stainless steel-screened covers. Water and food (Nuvilab CR1, Colombo, Paraná, Brazil) were provided ad libitum. All procedures were carried out in accordance with the conventional guidelines for experimentation with animals (GV-SOLAS 1985). The experimental protocols used in this study were approved by the Ethics Committee for Animal Experimentation at the State University of Rio de Janeiro.

Mouse infection procedures - Cercariae harvested from B. glabrata were used to infect 45 mice ( 7 day-old) by 
percutaneous route. Eighty cercariae were administered to each animal. Groups of five mice were euthanised by cervical dislocation at various time points from week three post-infection (pi) extending to nine weeks pi. Recovered flukes were processed for conventional bright field microscopy as follows: specimens were fixed in an alcoholformalin-acetic acid solution (AFA - alcohol 95\%, formalin and glacial acetic acid) and stained with hydrochloric carmine, clarified in methyl salicylate and preserved as whole-mounts (Neves et al. 1998).

Morphometric and morphological analyses - Worms were measured microscopically using computer image analysis (Image Pro Plus - Media Cybernetics, US) coupled to a Sony camera ( $640 \times 480$ pixels, RGB) using light microscopy (Olympus BX50). The following parameters were determined: body length, tegument in thickness, area of the oral and ventral sucker, and distance between them; perimeter, area, major and minor diameter, and number of testicular lobes and ovary (Neves et al. 1998). All measurements are in micrometers unless another one has been indicated. The dimension of organs represents arithmetic mean and standard deviation.

Confocal images (LSM-410, Zeiss), using a $543 \mathrm{~nm}$ $\mathrm{He} / \mathrm{Ne}$ laser and a LP 570 filter under reflected mode were used to study the reproductive system of males (testicular lobes) and females (ovary, uterus, ootype, and vitelline glands) (Neves et al. 2004).

Statistical analyses - Data analysis was performed using the Statistical Package for Social Sciences (SPSS) version 9.0. The one-way analysis of variance (ANOVA) and the post-hoc test of Tukey were used for comparision of groups. To assess correlations between variables Pearson correlation test was used. The acceptance significant level was $\mathrm{p} \leq 0.05$.

\section{RESULTS}

Five hundred seventy-five worms were studied throughout experiment. At week three, migrating parasites (81) were recorded in the lungs and liver. There was a heterogeneity regarding both morphometric features and degree of morphological development. The gynaecophoric canal, ootype, and ovary were evidenced from this week onwards (Table). The majority of male worms (47-59\%) presented gynaecophoric canal (Fig. 1A) whereas testicular lobes and tegumental tubercles were absent. Seven $(33 \%)$ female worms had an incipient ovary whereas only one specimen presented ootype (Fig. 2 A).

As infection progressed, developmental sequence of the reproductive system indicated that a maturation process was on going. At week four, all males (57-100\%) exhibited gynaecophoric canal, the majority $(44-77 \%)$ had testicular lobes, although few germinative cells were found (Fig. 1C). Male specimens (15-26\%) showed developing tegumental tubercles (Fig. 1B). At this time, eleven (69\%) females had a single ovary close to developing vitelline glands (vitellaria) (Fig. 2C). Almost all females (12-75\%) had an ootype and one specimen presented fertilized egg at initial stage of development (shell, first embryo, and vitelline cells) in the ootype. At week five, males presented developed testicular lobes (Fig. 1D). Almost all females
TABLE

Morphological features observed in worms recovered from albino mice over the course of infection (weeks)

\begin{tabular}{|c|c|c|c|c|c|c|c|}
\hline \multirow[b]{3}{*}{ Week } & \multicolumn{7}{|c|}{ Morphological characteristics } \\
\hline & \multicolumn{3}{|c|}{ Male } & \multicolumn{4}{|c|}{ Female } \\
\hline & $\mathrm{GC}$ & $\mathrm{TT}$ & TL & $\overline{\mathrm{VG}}$ & $\mathrm{OO}$ & $\mathrm{OV}$ & EG \\
\hline 3 & $P$ & A & A & A & $\mathrm{P}$ & $\mathrm{P}$ & A \\
\hline 4 & $\mathrm{P}$ & $\mathrm{P}$ & $\mathrm{P}$ & $P$ & $\mathrm{P}$ & $\mathrm{P}$ & $\mathrm{P}$ \\
\hline 5 & $\mathrm{P}$ & $\mathrm{P}$ & $\mathrm{P}$ & $P$ & $\mathrm{P}$ & $\mathrm{P}$ & $\mathrm{P}$ \\
\hline 6 & $\mathrm{P}$ & $P$ & $\mathrm{P}$ & $P$ & $\mathrm{P}$ & $\mathrm{P}$ & $\mathrm{P}$ \\
\hline 7 & $\mathrm{P}$ & $\mathrm{P}$ & $\mathrm{P}$ & $\mathrm{P}$ & $\mathrm{P}$ & $\mathrm{P}$ & $\mathrm{P}$ \\
\hline 8 & $\mathrm{P}$ & $\mathrm{P}$ & $\mathrm{P}$ & $\mathrm{P}$ & $\mathrm{P}$ & $\mathrm{P}$ & $\mathrm{P}$ \\
\hline 9 & $\mathrm{P}$ & $\mathrm{P}$ & $\mathrm{P}$ & $\mathrm{P}$ & $\mathrm{P}$ & $\mathrm{P}$ & $\mathrm{P}$ \\
\hline
\end{tabular}

P: presence, A: absence, GC: gynaecophoric canal, TT: tegumental tubercles, TL: testicular lobes, VG: vitelline glands, OO: ootype, OV: ovary, EG: egg.

(97\%) presented fully developed vitelline glands (Fig. 2D). Most females (73\%) presented only one egg sited in uterus or ootype. The ovary had cell differentiation, with smaller (immature) cells on the proximal region and bigger (mature) cells on the distal part of this organ (Fig. 2B). The fully developed reproductive system was observed from week six onwards.

The dimensions of the oral and ventral sucker observed in this study, were significantly different in juvenile flukes, but similar in ovigerous flukes. The size of suckers grew abruptly ( 3.0 fold) in male worms, however in females it increased only at 3-4 weeks when they became reduced in size. Females showed any variation regarding to the distance between suckers over the period of observation, whereas males weekly did $(\mathrm{p}<0.05)$.

Worm lengths increased with time post-infection although growth pattern was unequal between sexes. Whereas males had a significant growth $(p<0.05)$ until eight weeks, females tended stability earlier at week five. Males always showed thicker tegument than females. The growth of body length and all their organs and tegument. showed significant positive correlation $(p<0.05)$ in 4week old male. The Pearson test also showed significant positive correlation $(p<0.05)$ between the body length and the growth of ovary (area, perimeter and major diameter), except at week three since female worms devoid this organ. The sex ratio was male-biased: 2.3:1.

\section{DISCUSSION}

Together with inhabiting in sophisticated immune system in endothermic vertebrates and changes of the habitat, from arterial to venous blood, schistosomes evolved for separate genders (Platt \& Brooks 1997). This situation was not without constraints, however. The completion of the life-cycle required infective male and female cercariae which should find patterns of opposite sex mate within the vertebrate host. The evolutionary scenario invoked a number of morphological and physiological characteristics ensuring the successful reproduction in schistosomes. First, sex ratio of schistosomes is male-biased within the 
vertebrate host (Boissier \& Moné 2000, 2001, Freire et al. 2003). Although the adaptative explanation of this bias is unclear (Boissier et al. 2004), previous reports have suggested a strategy to ensure that all female would find a partner (Basch 1990, Platt \& Brooks 1997). Second, development of present-day-females is strongly dependent of male worms (Basch 1990, Ribeiro-Paes \& Rodrigues 1997, Kunz 2001). However, it appears to be realized into two phases which are male-indepedent or male-dependent (Hernandez et al. 2004).

There are many gaps concerning the male-independent phase of female growth within the vertebrate host. First, young male and female schistosomula are not morphologically distinctive. Second, tactile contact between young male-female schistosomula has never been described. Finally, if they share signals remain enignatic. Our results clearly show that, contrary to other accounts (Hernadez et al. 2004), the male-independent development takes less than one month. These results are to be expected given that age-specific changes are observed in surface topography and reproductive system of 3-male worm (McLaren 1980). At this time, male worm curves ventrally and overlaps its lateral margins forming the gynaecophoric canal (McLaren 1980). Therefore, our data demonstrated that mating occurs before sexual maturing (Table). In addition, division of labor between genders appears to occur earlier than adulthood.

While testicular lobes were not present, female worms have partly developed ovary and ootype. Earlier studies have evidenced two testicular lobes and a narrow uterus (Clegg 1965). Examination of whole-mount preparations using confocal microscopy has helped characterize novel details of the reproductive system of S. mansoni, modifying the adopted and current descriptions of the internal morphological structures (Neves et al. 2005). Although this lobes might not be perceptible by bright field microscopy, if present the tomographic analysis by confocal microscopy should have identified these structures due to its better resolution (Machado-Silva et al. 1998).

The male-dependent phase spans from immature worms until adulthood. In mouse worms, the major surface changes occur basically between weeks 4-5 after cercaria has entered the host's skin. The dorsal surface of 4-week male worm has a lot of tubercles to anchor them on the blood vessels as evidenced by scanning electron microscopy studies (McLaren 1980). From timing point of view, our observations indicate that tegumental tubercles are present in younger schistosomula as determined by con-
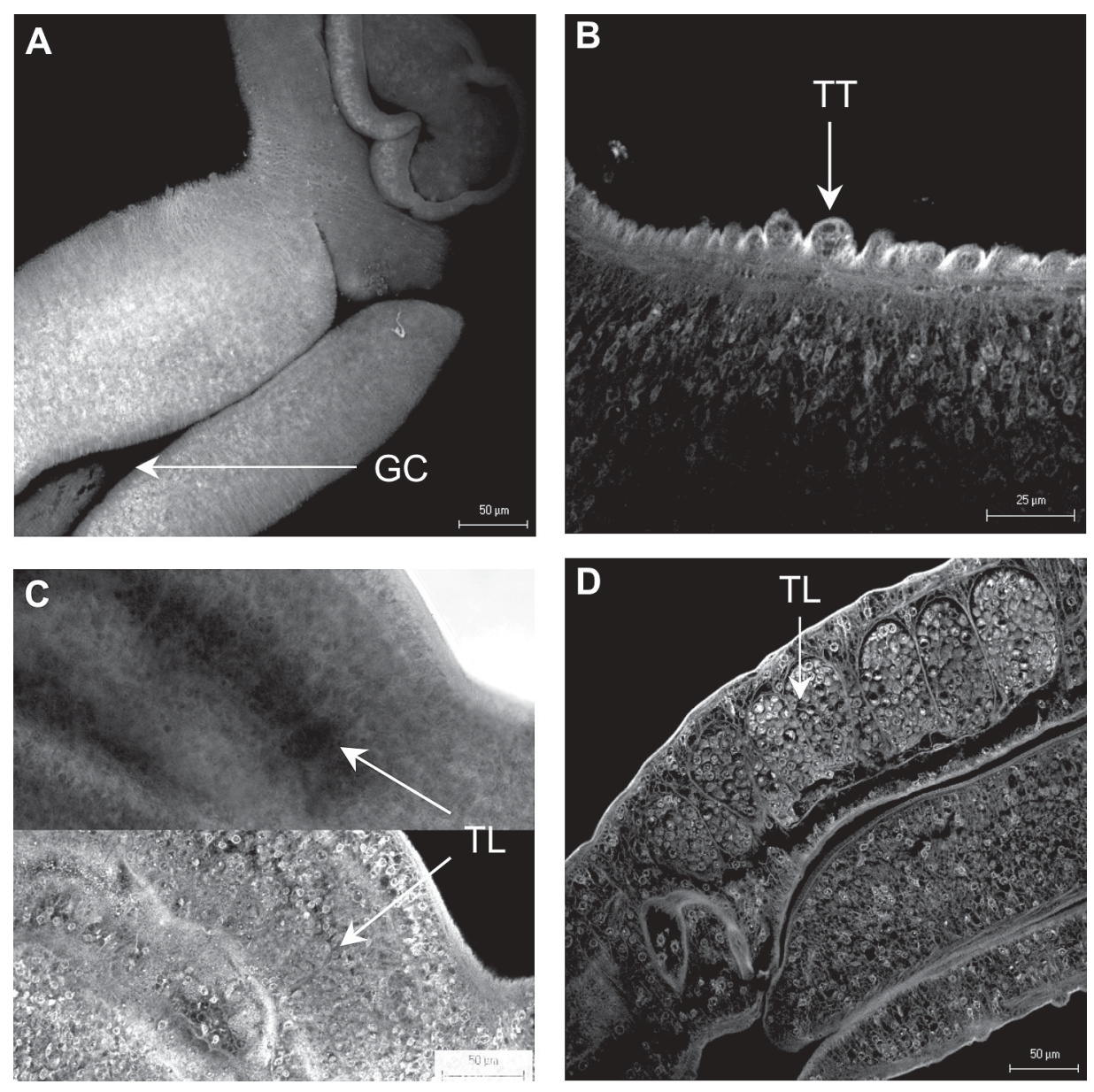

Fig. 1: confocal scanning laser microscope images of whole-mount preparations of male Schistosoma mansoni stained with hydrochloric carmine. A: 3-week-old; B and C: 4-week-old; D: 5-week-old; GC: gynaecophoric canal; TT: tegumental tubercles; TL: testicular lobes. 
focal microscopy. As development proceeded, the tegument increased in thickness so that males peaked around five weeks post-infection while females did earlier at week four. Moreover, male showed thicker tegument than females at any time of analysis. These results clearly stress morphological interplay between schistosome and its environment. The tegument is an important host-parasite interface (Abath \& Werkhausen 1996) due to its absorptive functions and exposition to the host's immune defence mechanism (Hockley 1973). Such localization would tend to protect lied females inside gynaecophoric canal from the hostile environment.

The imperative for reproductive efficiency compelled females to abandon unnecessary genetic baggage, including the whole package of determinants for maleness, plus most muscle and parenchyma tissue (Basch 1990), investing on predominantly in the production of eggs (Morand $\&$ Muller-Graf 2000). As a consequence, they significantly depend on the well-muscled males which control their feeding (Basch 1990, Ribeiro-Paes \& Rodrigues 1997, Oliveira et al. 2000, Kunz 2001) and sexual maturity (Basch 1990, Southgate et al. 1998, Kunz 2001). Various lines of evidence suggest that gene expression in the vitellaria of females is dependent on signals from the male sexual part- ner (LoVerde \& Chen 1991, Grevelding et al. 1997) and expression of the gene (p19) depends on pairing with a male (Michel et al. 2003). In short, there is a clear division of labor between male and female.

In this paper, fully developed reproductive system was observed from week six onwards. At this stage, gametogeny is on going and mating occurs (Clegg 1965, Popiel 1986, Ribeiro-Paes \& Rodrigues 1997, Kunz 2001). The gross phenotypic changes observed consist of increase in worm length, ovary maturation, development, and maturation of the vitteline glands (Erasmus 1986). Presented results showed that male and female worms followed different patterns of development after sexual maturation. Females grow only in the first weeks while males have a more prolonged growth until eight weeks. Until 50 week, the males were smaller than females and since then they were bigger than those. Clegg (1965) verified that females were smaller than males on day 28 , however they were bigger on day 35 . The ovary and testicular lobes measurements showed similar pattern sof development, suggesting this syncronious development may be more energetic advantageous. The gross changes in the reproductive system (area, diameter, and perimeter) were evidenced in 5 and 6-week worms.
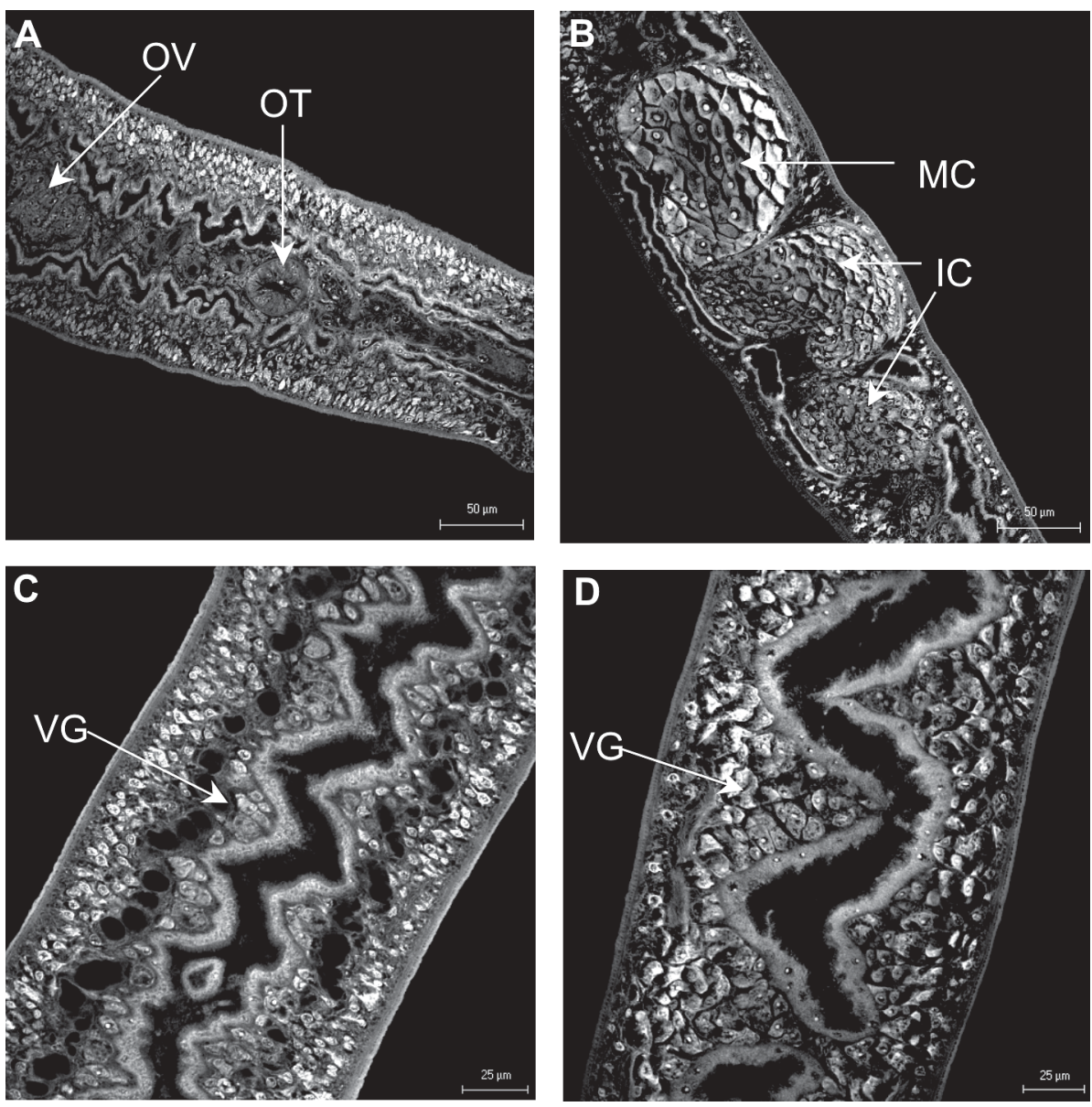

Fig. 2: confocal scanning laser microscope images of whole-mount preparations of female Schistosoma mansoni stained with hydrochloric carmine C. A: 3-week-old; B and D: 5-week-old; C: 4-week-old; OV: incipient ovary; OT: ootype; MC: mature ovary cells; IC: immature ovary cells; VG: vitelline glands. 
A strikingly finding was demonstrated when suckers were analyzed. Males peaked development at week 8 while females also showed an initial increase, peaking at week 4 , however they became reduced in size thereafter. Since females have mated on the fourth week, they are passively carried on the male's gynaecophoric canal thereafter, so that suckers are not required for migration and fixation. As a consequence, these structures could be atrophied or have their size reduced. In addition, female's suckers are not muscular as males, the tegumental tubercles, if any, are spineless and unremarkable in texture (Neves et al. 2005). We may reasonably infer that all these features are from evolutive traits. In the present study, all recovered worms were paired. This study provided interesting insight into the biology of schistosomes. In conclusion, events observed during the male-dependent phase are morphological traits which schistosome has experienced from hermafrodite to dioecy.

\section{ACKNOWLEDGMENTS}

To Dr Lygia dos Reis Corrêa for S. mansoni cercariae, Department of Malacology; Dr Henrique Leonel Lenzi and Thiago Branquinho for facilities with confocal images, Department of Pathology, Instituto Oswaldo Cruz.

\section{REFERENCES}

Abath FGC, Werkhauser RP 1996. The tegument of Schistosoma mansoni: functional and immunological features. Parasite Immunol 18: 15-20.

Basch PF 1990. Why do schistosomes have separate sexes? Parasitol Today 6: 160-163.

Boissier J, Moné H 2000. Experimental observations on the sex ratio of adult Schistosoma mansoni, with comments on the natural male bias. Parasitology 121: 379-383.

Boissier J, Moné H 2001. Relationship between worm burden and male proportion in Schistosoma mansoni experimentally infected rodentsand primates. A meta-analytical approach. Int J Parasitol 31: 1597-1599.

Boissier J, Jarkovsky J, Morand S, Moné H 2004. A model to explain the origin of a parasite sex-specific population structure. Theor Popul Biol 66: 269-276.

Clegg JA 1965. In vitro cultivation of Schistosoma mansoni. Exp Parasitol 16: 133-147.

Erasmus DA 1986. Structural and metabolic changes in female Schistosoma mansoni following male stimulation. J Chem Ecol 12: 1755-1764.

Freire N, Rodrigues-Silva R, Machado-Silva JR, Rey L 2003. A comparative parasitologic study on Biomphalaria glabrata snail and $\mathrm{C} 3 \mathrm{H} / \mathrm{He}$ mice infected with human and murine isolates of Schistosoma mansoni derived from Sumidouro, Rio de Janeiro, Brazil. Mem Inst Oswaldo Cruz 98: 783787.

Grevelding CG, Sommer G, Kunz W 1997. Female-specific gene expression in Schistosoma mansoni is regulated by pairing. Parasitology 115: 635-640.

GV-SOLAS - Working Committee for the Biological Characterization of Laboratory Animals 1985. Guidelines for specification of animals and husbandry methods when reporting the results of animal experiments. Lab Anim 19: 106-108.

Hernandez DC, Lim KC, McKerrow JH, Davies SJ 2004. Schistosoma mansoni: sex-specific modulation of parasite growth by host immune signals. Exp Parasitol 106: 59-61.

Hockley DJ 1973. Ultrastructure of the tegument of Schistosoma. Adv Parasitol 11: 233-305.

Kunz W 2001. Schistosome male-female interaction: induction of germ-cell differentiation. Trends Parasitol 17: 227-231.

LoVerde PT, Chen L 1991. Schistosome female reproductive development. Parasitol Today 7: 303-308.

Machado-Silva JR, Pelajo-Machado M, Lenzi HL, Gomes DC 1998. Morphological study of adult male worms of Schistosoma mansoni Sambon, 1907 by confocal laser scanning microscopy. Mem Inst Oswaldo Cruz 93: 303-307.

McLaren DJ 1980. Schistosoma mansoni: The Parasite Surface in Relation to Host Immunity, Research Studies Press, US, $229 \mathrm{pp}$.

Michel A, Knobloch J, Kunz W 2003. P19: a female and tissue specifically expressed gene in Schistosoma mansoni, regulated by pairing with the male. Parasitology 127: 519-524.

Morand S, Müller-Graf CDM 2000. Muscles or testes? Comparative evidence for sexual competition among dioecious blood parasites (Schistosomatidae) of vertebrates. Parasitology 120: 45-56.

Neves RH, Pereira MJS, Gomes DC, Oliveira RMF, MachadoSilva JR 1998. Morphometric differences of adult worms from sympatric samples of Schistosoma mansoni Sambon, 1907 isolated from rodents and humans. Mem Inst Oswaldo Cruz 93: 309-312.

Neves RH, Costa-Silva M, Martinez EM, Branquinho TB, Oliveira RMF, Lenzi HL, Gomes DC, Machado-Silva JR 2004. Phenotypic plasticity in adult worms of Schistosoma mansoni (Trematoda: Schistosomatidae) evidenced by bright-field and confocal laser scanning microscopy. Mem Inst Oswaldo Cruz 99: 131-136.

Neves RH, Biolchini CL, Hulstijn M, Carvalho JJ, Gomes DC, Branquinho TB, Lenzi HL, Machado-Silva JR 2005. New description of the reproductive system of Schistosoma mansoni (Trematoda:Schistomatidae) analyzed by confocal laser scanning microscopy. Parasitol Res 95: 43-49.

Oliveira MF, d'Avila JC, Oliveira PL, Tempone AJ, Rumjanek, FD, Braga, CM, Silva, JR, Dansa-Petretsk M, Oliveira, MA, de Souza W, Ferreira ST 2000. Haemozoin in Schistosoma mansoni. Mol Biochem Parasitol 111: 217-221.

Platt TR, Brooks DR 1997. Evolution of the schistosomes (Digenea: Schistosomatoidea): the origin of dioecy and colonization of the venous system. J Parasitol 83: 1035-1044.

Popiel I 1986. Male-stimulated female maturation in Schistosoma: a review. J Chem Ecol 12: 1745-1754.

Ribeiro-Paes JT, Rodrigues V 1997. Sex determination and female reproductive development in the genus Schistosoma: a review. Rev Inst Med Trop São Paulo 39: 337-344.

Southgate VR, Jourdane J, Tchuem Tchuenté LA 1998. Recent studies on the reproductive biology of the schistosomes and their relevance to speciation in the Digenea. Int $J$ Parasitol 28: 1159-1172. 
